\title{
Is Virtual-Physical or Physical-Virtual Manipulatives in Physics Irrelevant within Studio Physics Environment?
}

\author{
By Jean-Pierre Atanas*
}

\begin{abstract}
The purpose of this study is to explore factors that affect exclusively physical, virtual and both a Virtual-Physical (VP) and Physical-Virtual (PV) sequence of manipulatives within Studio Physics environment. In this environment students actively work together to learn through real world experimentation and simulation based activities. Activities and tests have been especially designed for that purpose. Students, from different sections and for two consecutive academic years, have been involved in the study. Statistics show that comprehensive learning groups (i.e. any combination of PV or VP sequence) performed better than any other setting. The study also pinpoints the importance of the sequence for which virtual or physical experiments of some specific concepts are initially introduced to students.
\end{abstract}

Keywords: comprehensive activities, conceptual physics, PV and VP sequences, studio physics.

\section{Introduction}

In recent years, approaches to teaching have radically changed and have led to a major difference between teaching in the traditional way and active learning such as in the "Studio Physics" environment (Cummings, Marx, Thornton, \& Kuhl, 1999; Furtak \& Ohno, 2001, Sorensen, Churukain, Maleki, \& Zollman, 2006). Literature which investigated learning (Miner, 2010; Linn, Lee, Tinker, Husic, \& Chiu, 2006; Prince, 2004), have promoted awareness about the different kind of learning styles, characteristics, strengths and preferences in the ways students acquire and process information. Although the theory of learning styles has been used in other educational domains, many practitioners and experts in the field of science and engineering education have also noted the importance of teaching while accommodating learning styles. A variety of characteristics impact student's performance and ultimately individual effectiveness (Chen \& Chang, 2016; Giddens, 2014; Harden-Thew \& Lawson, 2015; Jegatha, Baskaran, \& Kannan, 2014; Rogowsky, Calhoun, \& Tallal, 2015; Tan \& Laswad, 2015) hence achievements in the classroom. The main characteristics are as follows:

- Intelligence, achievement, and prior knowledge

- Learning style

- Cognitive development

* Professor, Khalifa University of Science and Technology, Department of Physics, UAE. 
- Gender

- Race

- Moral and character development

All these characteristics are addressed by most of the active learning environments including the Studio Physics environment. Active learning in Studio Physics is a process whereby students engage in activities, such as reading, writing, group discussion, or problem solving that enhance analysis, synthesis, and evaluation skills of the student. Some of the approaches that promote active learning are cooperative learning, problem-based learning, case study methods and simulation-based activities. Active learning requires an extensive use of many learning technologies such as Audio and Video contents, computers, tablets and mobile devices, whiteboards, Screen-casting, Virtual Learning Environments (VLE), clickers, Learning Management System (Blackboard TM, Moodle TM, etc.) and Computer-aided assessments, just to name a few. Researchers may disagree about using all kind of learning technologies in an excessive way that becomes a real burden to students or a purpose by itself, thus hindering the process of achieving an efficient active learning environment. Nevertheless, all researchers agreed to use at least one or two learning technology tools to serve their purposes even in the traditional way of teaching. Benefits of incorporating new technologies in the classroom or in the Studio environment may include: student motivation (Guo, Li, \& Stevens, 2012), easy-to-access course materials (US Department of Education, 2011) and differentiated instructions (Ross, Morrison, \& Lowther, 2010). Research in educational technology, addressed learning style diversity, improved student writing, encouraged better participation and feedback, increased focus, improved time management, and allowed more opportunities for extended learning. Many drawbacks may arise from an excessive or obsessed use of technology. According to Postman's (Postman, 1995) claim: "it is more important for learners to reflect on the implications and consequences of the process of information gathering, than it is to simply to acquire the skills to generate, receive, gather and distribute information in easier and faster ways".

\section{The Physics Education at the Petroleum Institute (PI)}

Here, in the Petroleum Institute (PI), freshman students have a different level of knowledge in science and mathematics. After passing the first academic year, students would probably acquire the basic knowledge and the appropriate skills required to continue with more specialized topics in science and engineering. During that first year, students would have been exposed to various modern technologies such as computers, learning packages, data acquisition software and interfacing devices used in classrooms and laboratory or Studio facilities. Many efforts have been conducted recently to promote and apply the use of technology in the classroom. Classrooms has been redesigned, refurbished and transformed into smart classrooms equipped with the latest state of the art touch screen boards or smart boards, audio sound systems, and 
most importantly, seats arranged in groups of five, as in Figure 1, to facilitate group discussions, student interactions and group work.

\section{Figure 1. Snapshot of the Newly Refurbished Smart Classrooms at PI}

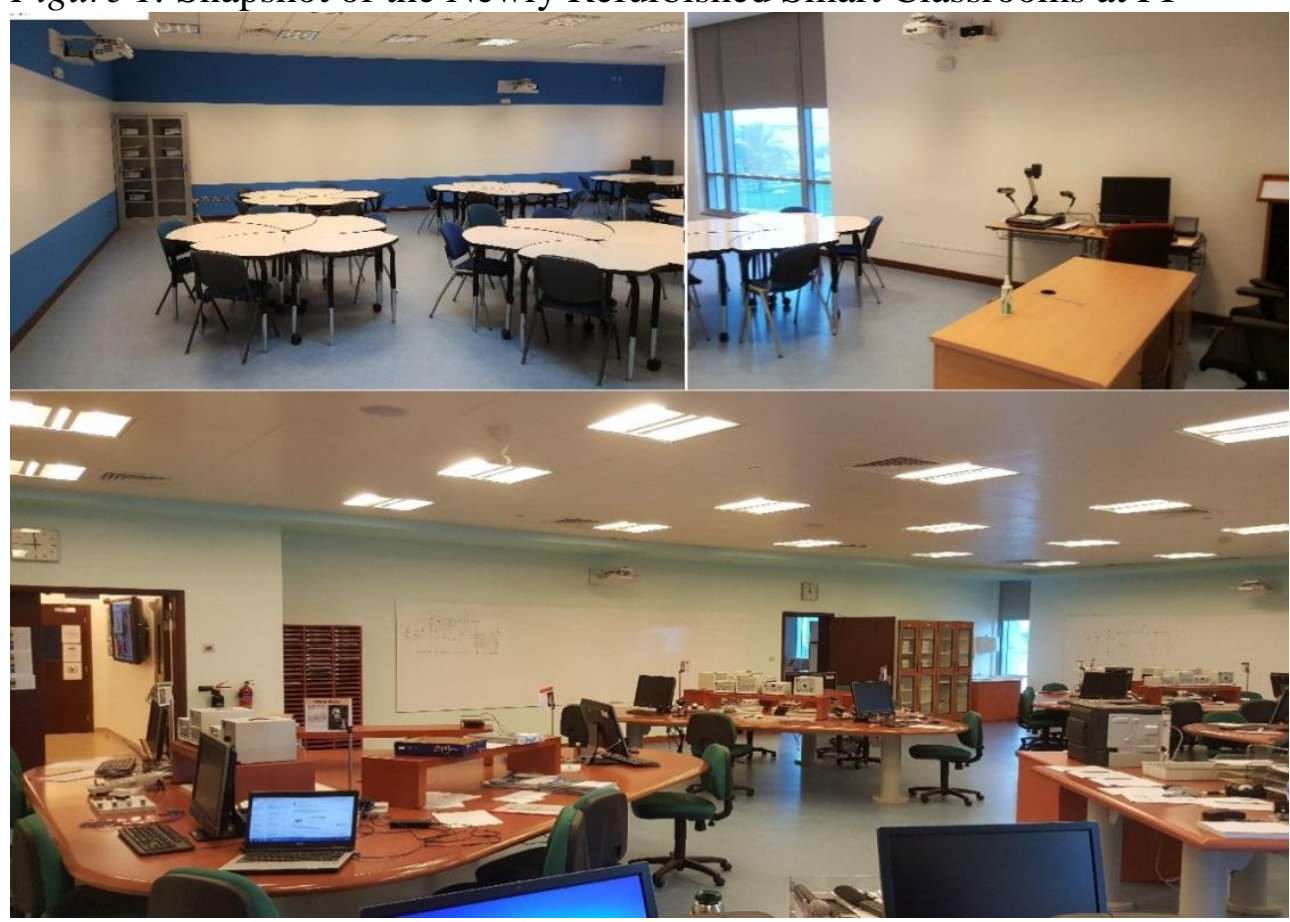

The class environment simulates those specifically designed for studio physics classrooms. A studio physics approach was mainly applied to freshman students at the PI since 2012. Although at first, students were reluctant to change, however, they adapted to the new environment shortly after. During the past years, performance has been measured since the application of Studio Physics as a new approach in teaching and learning. The results were very encouraging.

\section{Sequence of Manipulatives to be tested in Studio Environment}

Recently legitimate questions were raised about using the Studio Physics approach in sophomore where a higher level physics course is introduced, such as Physics II: "Electromagnetism and Optics". It was noticed that students have difficulty to grasp concepts related to electromagnetism and optics, especially when microscopic dimensions of the physical phenomena were involved. In mechanics, most of them belong to the macroscopic world and were mostly about observations made in nature. Concepts were relatively easy to grasp. Since Studio Physics is an active environment which engages students in physical and virtual activities, it was decided to transform the physics II course and associated laboratories to Studio environments. Laboratory activities supported the learned concepts whereby students were able to observe, touch and setup experiments with their bare hands. Although in electromagnetism 
and Optics, students were also using their kinesthetic elements and cognitive skills in most of the experiments, however, they were not able to understand physical concepts at the microscopic levels (i.e., electrons circulation inside resistors, origin of resistance, electromagnetic radiations, etc.). Many optimistic claims have been heard about virtual reality (simulation based activities, interactive 2D and 3D virtual environments, coach, desktop virtual reality (DVR) and simple intelligence and its positive impact on learning conceptual science (Merchant, Goetz, Cifuentes, Keeney-Kennicutt, \& Davis, 2014; Huppert, Lomask, \& Lazarowitz, 2002; Zacharia \& Anderson, 2003; Couture, 2004; Finkelstein et al., 2005; De Jong, Linn, \& Zacharia, 2013). Several advantages of using virtual experiments were recorded especially when the topic of the session had to do with concepts and contexts outside the everyday experience (Koretsky, Kelly, \& Gummer, 2011). However, virtual activities do not necessarily guarantee conceptual learning as in (Renken \& Nunez, 2013). Based on the aforementioned research, the effectiveness of introducing virtual experiments are beneficial to some extent to the conceptual learning process and can add different dimensions to the learning of physical concepts. In this paper, introducing manipulatives in a given sequential order Virtual-Physical (VP) or Physical-Virtual (PV) within Studio Physics environment is being measured and assessed. This study complements prior research (e.g. Finkelstein, et al., 2005; Klahr, Triona, \& Williams, 2007; Zacharia, 2005; Zacharia \& Anderson, 2003), which has not reached a resolution or a clear consensus on the relative effectiveness of virtual and physical activities on student conceptual learning and contradicts a recent research (Carmichael, 2010) claiming that only one sequence Physical-Virtual (PV) is the most effective way of learning concepts. The outcome of this study shows that the most effective learning could be both ways Virtual-Physical (VP) or PhysicalVirtual (PV) depending on the concepts being learned.

\section{Experimental Design}

The defining characteristics of studio physics classes undertaken now at PI are in integrated lecture/laboratory form, with a substantial reduction in lecture time, a high level of student-student interaction, a technology-enhanced learning environment, and a collaborative group work. This process has been guided by our experience with Physics I (Introduction to Physics: Mechanics). A conversion of "Physics II: Electromagnetism and optics" to a Studio format has been initiated recently.

\section{Participants and Environment}

The maximum capacity of a Studio Physics classroom is $\mathrm{N}=36$ with at least a faculty and two trained teaching assistants (TAs) facilitating the conceptual learning through especially designed activities either with virtual experiments (simulation-based activities) or with physical experiments (hand- 
on activities). Students enrolled in physics II course will have three days per week short lectures, each of fifty minutes, where faculty members introduce the subject in an interactive way. The other two days each one hour and a half laboratory session, are supervised by the faculty member himself supported by two teaching assistants. The 4-credit course content is spread over a fifteenweek interval. Most of the simulation-based experiments or virtual activities were developed and designed based on "PhET" (Physics Education technology) interactive applets. Great care has been taken to develop questions around a given concept(s). "PhET" simulations were developed by the University of Colorado which uses computers while addressing some useful concepts in physics (Perkins et al., 2006). They were designed to be highly interactive, engaging and facilitating the learning of concepts.

\section{Activity Design}

Activities used in the laboratory were designed to introduce briefly the topic after listing clearly the goals. If the activity is a real physical experiment, a short paragraph describes the setup with a schematic diagram, otherwise, it will be a virtual one and the setup part will be either omitted or replaced with a set of instructions about the utilization of the applet. Afterwards, a series of tasks and questions are followed in both types of activities. Despite the running experiment real or virtual, tasks are short procedures that the student has to accomplish either by setting up the activity in a physical experiment or by configuring "PhET" applets with appropriate settings. This set of tasks and questions was carefully designed in a sequential manner to reach smoothly the objectives already set for the activity. Every student was given an individual notebook to record detailed answers to questions before the end of the session. Finally, an optional challenging question is assigned to those who finish the activity early. Students have to read and understand the objectives set at the beginning of the activity. They may interact with each other or with TAs to seek some clarifications for their queries without getting any direct answers or hints to the proposed questions. Faculty members and TAs are just facilitators and offer occasionally their technical support when necessary. The test and control conditions were assigned in order to isolate effects of the TAs and to include similar cross sections of students in the course. Reading comprehension is the first skill students are required to develop during activity workouts. Students were also instructed to include their written answers with great details and were encouraged to include sketches, diagrams, charts and graphs on their notebook for clarity purposes and hence to get better scores. The marking of their notebook is performed, uniformly across all sections, using a clear assessment rubric designed by both faculty and teaching assistants. Finally, the majority of the activities are exclusively physical experiments or virtual ones. The remaining activities are comprehensive where both types of manipulatives (i.e. PV and VP sequences) are being offered in specific weeks and in a specific topic as shown in Table 1. 
Table 1. Title of Activity Assigned Weekly with their Sequence P, V, PV or VP

\begin{tabular}{|c|c|c|c|c|c|}
\hline & Title of the Activity & \multicolumn{2}{|c|}{2013} & \multicolumn{2}{|c|}{2014} \\
\hline Week1 & Coulombs' Law & \multicolumn{2}{|c|}{$\mathrm{P}$} & \multicolumn{2}{|c|}{$\mathrm{P}$} \\
\hline Week2 & Electric field lines & $\mathrm{P}$ & $\mathrm{V}$ & $\mathrm{V}$ & $\mathrm{P}$ \\
\hline Week3 & Gauss law for electric fields & \multicolumn{2}{|c|}{$\mathrm{V}$} & \multicolumn{2}{|c|}{$\mathrm{V}$} \\
\hline Week4 & Electric potential & $\mathrm{P}$ & $\mathrm{V}$ & $\mathrm{V}$ & $\mathrm{P}$ \\
\hline Week5 & Parallel plate capacitor & \multicolumn{2}{|c|}{$\mathrm{P}$} & \multicolumn{2}{|c|}{$\mathrm{P}$} \\
\hline Week6 & Resistance and resistivity & \multicolumn{2}{|c|}{$\mathrm{P}$} & \multicolumn{2}{|c|}{$\mathrm{P}$} \\
\hline Week7 & RLC circuits & \multicolumn{2}{|c|}{$\mathrm{V}$} & \multicolumn{2}{|c|}{$\mathrm{V}$} \\
\hline Week8 & Magnetic forces & \multicolumn{2}{|c|}{$\mathrm{P}$} & \multicolumn{2}{|c|}{$\mathrm{P}$} \\
\hline Week9 & Polarization, refraction and reflection of light & $\mathrm{P}$ & $\mathrm{V}$ & $\mathrm{V}$ & $\mathrm{P}$ \\
\hline
\end{tabular}

\section{Procedure}

Each of the twelve sections of the physics II course are involved in this study and take all activities during a regular semester of sixteen weeks. Sections are not split into two groups to test the PV and VP sequences, however, it is decided, in order to ensure uniformity across all sections, that six from each academic year 2013 and 2014, will participate to the test whereby the sequence of manipulatives were completely reversed from one year to another, as shown in table 1 . Performances in exclusively physical or virtual activities will be compared to the comprehensive ones, where both VP and PV manipulatives are taken in the same week regardless of the sequence. All exclusive and comprehensive activities are distributed over nine weeks. The remaining weeks are reserved for online problem solving activities, covering various concepts, and for assessment purposes. It is worth noting that splitting sections into two groups, each belonging to a sequence, doesn't guarantee necessarily fairness or uniformity throughout the sections. It is decided to choose one sequence from an academic year and then reverse it in the next, hence maintaining uniformity in the learned concepts among all sections for a given academic year. All activities, equipment, contents, facilities, faculty and staff members were unchanged during these two consecutive years. The grades for each student in the group were recorded and marked according to a clear, transparent and uniform assessment rubric. The procedure doesn't rely on per question basis assessment but rather on a holistic approach where the overall score attributed to each activity is considered. The holistic procedure was selected since questions can differ slightly from virtual to real experiments. However, at the end, the objectives reached were identical.

\section{Data Collection}

The following data was collected and analyzed for the two academic years mentioned above during the course of this study.

a. Observational notes and comments made on a particular question or for some activities in general by both faculty members and (TAs).

b. Overall performance for the activity in question. 
c. Challenging problems at the end of each activity.

\section{Results}

Collected data was transferred to Minitab ${ }^{\circledR}$ for further analysis. All exclusive physical and virtual activities were analyzed at first before testing the effect of any sequence VP or PV on students' performance. Table 1 shows three physical and only two virtual activities that were completed during a regular semester. All remaining activities were comprehensive. Figure 2 shows the average grade per activity for both exclusively physical and exclusively virtual activities lying between $71 \%$ and $77 \%$.

Figure 2. Average Grade per Activity in Percentage for Both Years 2013 and 2014

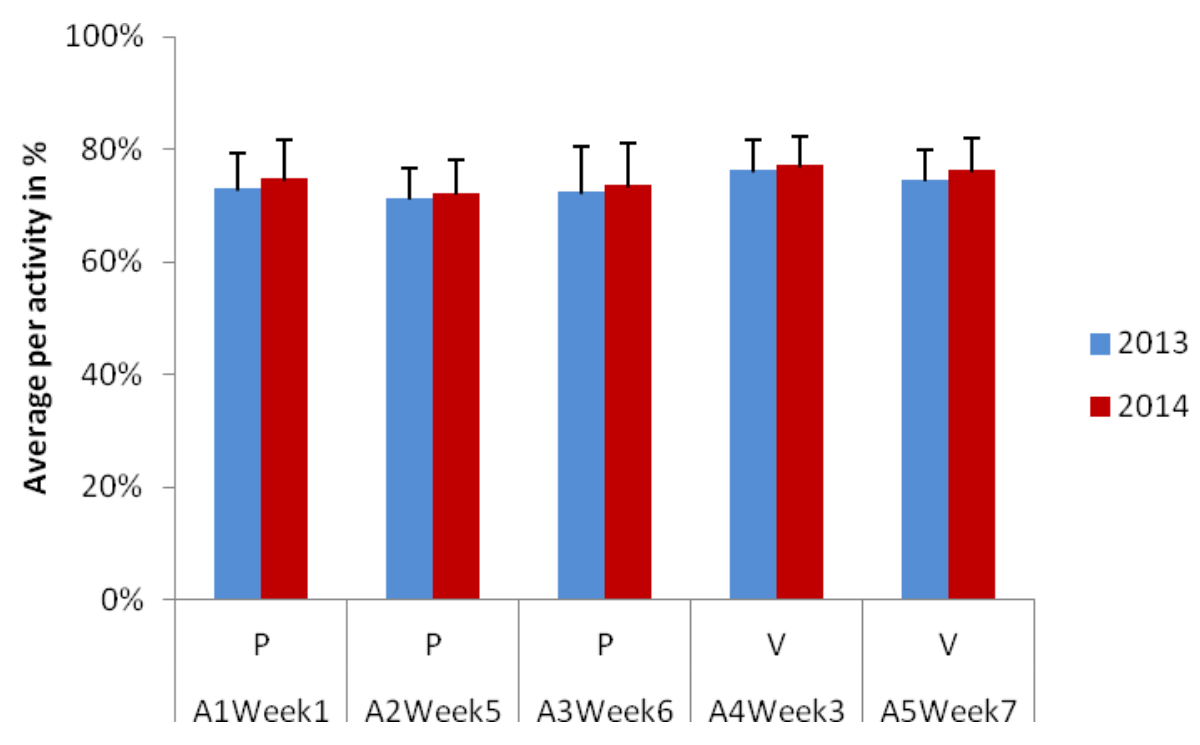

Our first goal in the analysis of results is to identify whether a substantial improvement was achieved for physical or virtual activities taken exclusively by students during the consecutive years 2013 and 2014 .

The group of 183 students involved in the study was nearly homogenous. Although students in each section might not constitute a homogeneous group, however, the overall performance measured for each year in physics II was similar. A 2-Sample $t$-test for the mean performance across exclusively physical or virtual activities from one year to another shows no statistical significant difference at the $\mathrm{p}<0.01$ level. This result infers no tangible improvement or progress being made during the two consecutive years when a physical or virtual activity has been administered exclusively to students. It was also important to determine whether the average grade of a VP sequence differs from that of an exclusive activity in any of the academic years. A 2-Sample $t$-test for the average grade ran across all the VP activities and was compared to the exclusive ones. Results show a statistical significant difference to a $p<0.1$ level. Since the average scores for the VP activities were higher than the 
exclusive counterparts, one can ascertain that students were better prepared for the experimental activities in the comprehensive setting. Introducing simultaneously virtual and physical activities within the same week has increased the ability of students to better understand the physical experiment and the concepts behind. In the following, average scores per activity for different sequence are also shown in Figure 3. In order to quantify the difference between the average scores per activity for a given sequence, the quantity "RAD" (e.g. Relative Average Difference per activity for each sequence VP or PV) has been calculated. "RAD" formulas for each sequence used are as follows:

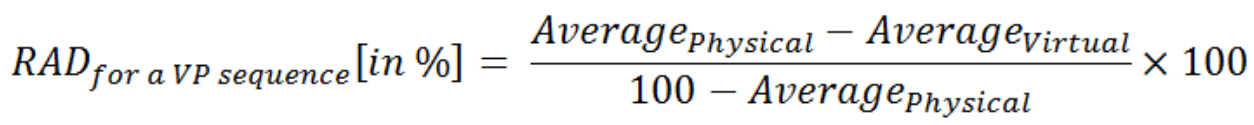

$$
\begin{aligned}
& R A D_{\text {for a PV sequence }}[\text { in } \%]=\frac{\text { Averag }_{\text {Virtual }}-\text { Average }_{\text {Physical }}}{100-\text { Average }_{\text {Virtual }}} \times 100
\end{aligned}
$$

Figure 3. Average Grade per Activity for Different Sequences in 2013 and 2014
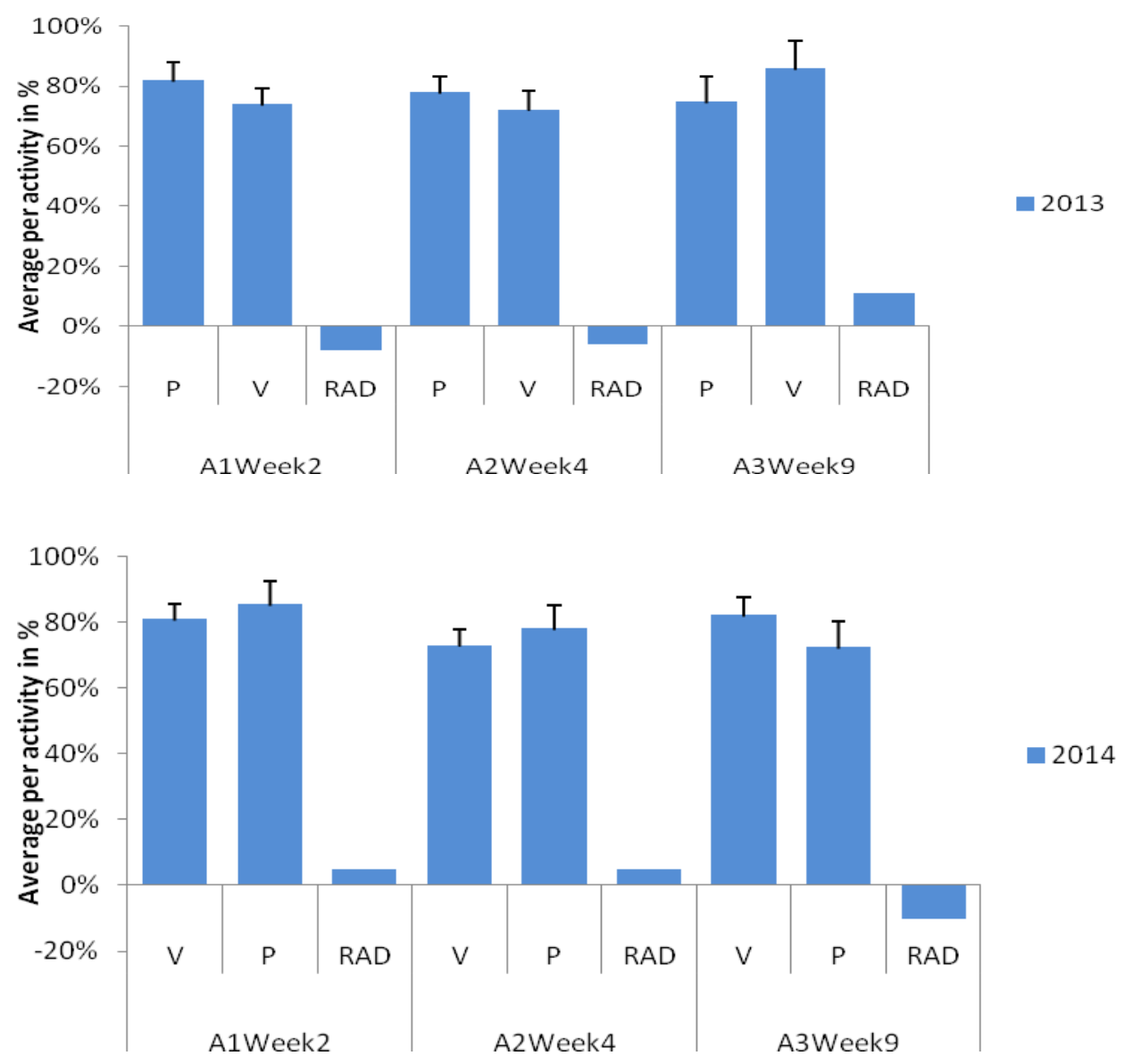

"RAD" has been converted to percentage for convenience. For 2013, and 
according to Figure 3, the PV sequence was chosen for both activities (A1Week2 and A2 Week4) in the first 2 weeks and shows a negative "RAD", except for the last one (A3Week9), where the "RAD" is around 10\%. Negative "RAD" obtained for both activities, in the first 2 weeks, suggests that no gain was obtained by introducing the physical experiment first, hence the sequence PV for these two activities was ineffective. However, when the sequence is reversed (i.e. VP) in the following year 2014, a positive "RAD" has been obtained and a gain in the conceptual learning has been recorded. This inference remains incomplete unless a statistical significant difference is found for both sequences. A 2-Sample $t$-test for the mean's difference between average scores, for both years, in PV and VP distributions is applied.

As a result, both differences in each year are statistically significant at the $p<0.01$ level. This is to confirm the previous inference. It is striking to notice that for the third activity in Week 9, the "RAD" is reversed suggesting that the gain obtained in introducing the physical experiment first is more effective for this particular activity. Consequences of this conceptual understanding are being supported by a significant increase of the average scores in the virtual activities as shown in Figure 3, year 2013. This result was initially counter intuitive, as we thought that the sequence VP, in Figure 3 for year 2014, will always be advantageous over any other setting, since students will be well prepared after a virtual activity and consequently will achieve better on the physical one. However, a deeper look into topics of activities in weeks 2 and 4 reveals abstract concepts pertaining to the microscopic world, (i.e., electric fields and potentials concepts). Students have difficulty visualizing virtual lines when running the physical experiment. They simply couldn't visualize lines of fields or equipotential lines out of the physical activity. They measure indirectly a voltage through a voltmeter as shown in Figure 4 and search heuristically for points having the same voltage which they label later on "equipotential lines". Add to it, that most often student have had many difficulties to setup the experiment. Students can't relate both electric potential and electric fields, they think only about the measurement which is the electric potential here. The electric field is not measured directly. Students were confused about how one can derive the electric field while measuring the electric potential. They need to go through the theory of fields were the electric field derives from a potential. Just then students were able to draw the lines of the electric field. Once found, electric field lines are derived indirectly as being perpendicular to these equipotential lines. In the virtual activity, these lines are completely visualized, as soon as conductors (i.e. made of series of charges), are dragged inside the drawing area. 
Figure 4. Physical Experiment at PI Laboratory (top) versus the Virtual Activity from PhET Simulations Perkins, K.K. et al., 2006 (bottom)

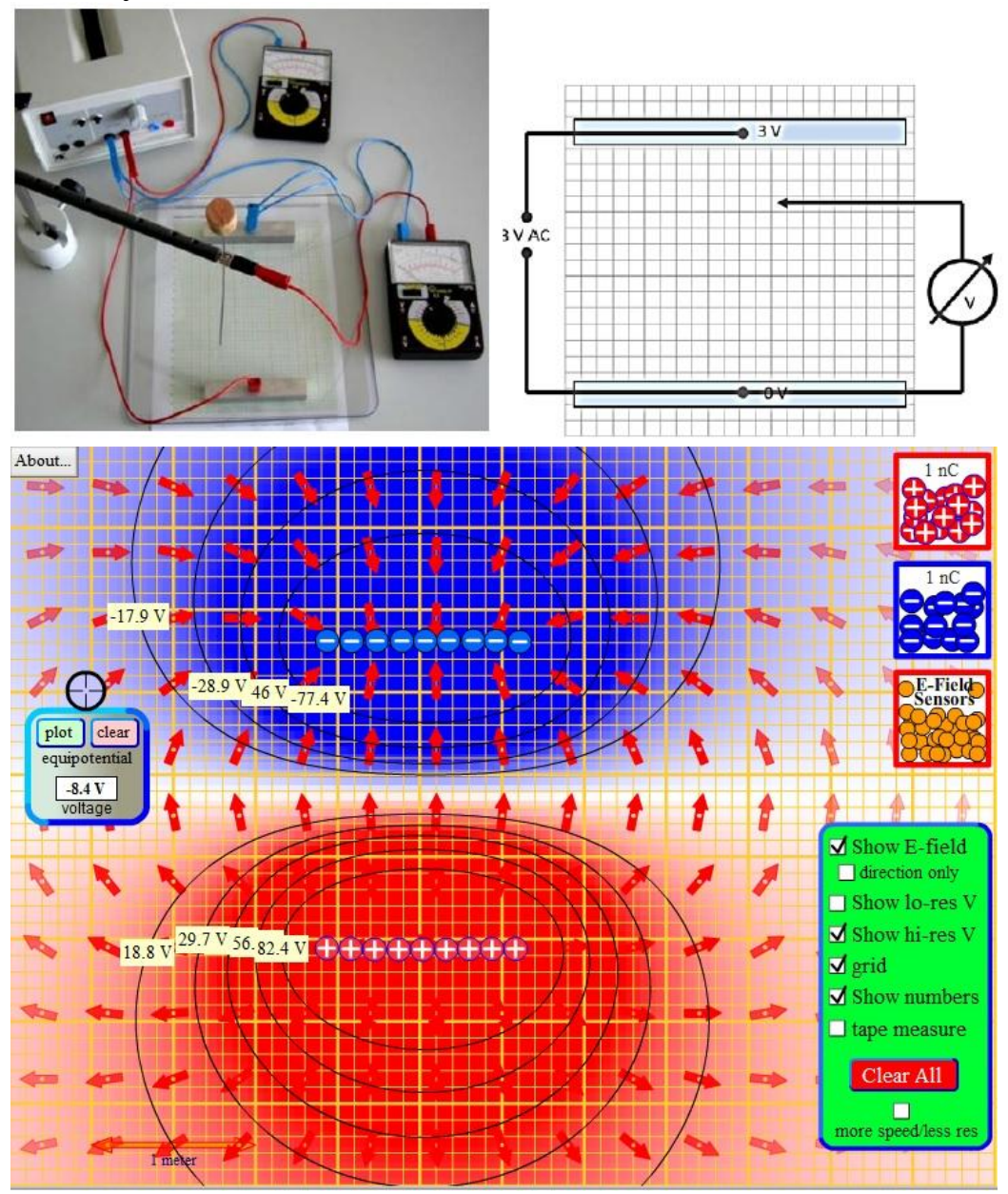

These lines are physically represented with a particular line shape where potentials differ from line to line. Arrows representing directions of the electric field are also shown. One can see clearly the orientation of the electric field, away from the positive charge in red and toward the negative charge in blue. An electric potential sensor is also shown on the left side of the figure. Students can drag it everywhere in the drawing area to read the electric potential. They can easily relate electric field variations with the electric potential change and establish visually the relation between electric field and electric potential. In the virtual activity, when the electric charge density is varied, lines of field and their numbers are immediately seen in the drawing area. Students will be able to track these changes and will have a ready-model in their mind of what to expect in the physical experiment. Identifying these virtual lines becomes easier, hence the concept of electric field lines or equipotential lines will be much easier to grasp. Comments recorded by TAs confirm this fact. According to them, time needed to finish a physical experiment after introducing the virtual one was shorter than the PV sequence. Also, all comprehensive activities with either a VP or PV sequence took less time than any other exclusive physical 
or virtual activity. Unfortunately, this confirmation is based on notes and comments formulated by faculty and staff members. No time recording was undertaken to confirm the previous comments. By opposition, the last activity topic which was about polarization, refraction and reflection of light shows different result. Although light could be considered as belonging to the microscopic world, however, laser light could be ray traced easily. No quantum knowledge requirement was necessary to understand these phenomena. Only the classical aspect of light polarization (i.e., change of the electric field direction) and the propagation of light either by reflection or refraction through a medium is being considered. Comments about students' questions when the virtual activity was given first were mostly about the polarizer, its shape, the type of material being used, and the variation of the polarization angle. The need to setup physically the experiment with a real polarizer was essential to the students' conceptual learning and understanding process. Average scores for the PV sequence as well as the positive RAD, in Figure 3 for the 2014 academic year, confirm it.

\section{Discussion}

The results concerning the sequence of physical and virtual experiments show that conducting the physical experiment followed by the virtual depends on the topic being studied. Researchers more prone to physical experiments first do not relate it to the scientific context, degree of student perception, the learning styles with their main characteristics and most importantly the degree of abstraction of the scientific concept being studied. This would explain why Zacharia, Olympiou and Papaevripidou (2008) claim that physical experimentation is likely to have more advantages in domains requiring "physical manipulation and tactile sensation". The same authors, in other studies exploring the combination of physical and virtual experiments (Zacharia \& Anderson, 2003) have had students explore a simulation environment prior to performing a physical investigation. The theoretical rationale for this is that the computer simulation serves as a "cognitive framework", allowing students to first understand theoretical principles (Jaakkola \& Nurmi, 2008) and later apply them to a real-world inquiry. Simulation-based activities should serve as a cognitive framework for enhancing the subsequent more open-ended inquiry learning in the subject matter domain of the experiments (Zacharia \& Anderson, 2003). Having students conduct virtual experiments through computer simulations after conducting physical experiments can lead to enhanced student conceptual understanding. These contradictions and differences imply that either both sequences are advantages, yet to know why and how to design and present the scientific concepts, or both sequences are irrelevant. This study shows clearly that both sequences are advantages if they were adapted to the scientific concepts, learning styles and most importantly the degree of abstraction of the studied topic. The results, in this paper, show a gain in performance when virtual-then-physical experiments were designed for abstract concepts or 
belong to the microscopic hidden world beyond the human sensory percepts (e.g.; electric field and potential, electric circuits, resistance and resistivity, Amperes Law of magnetism, Maxwell equations, etc.) and also the opposite where physical-then-virtual experiments are more advantages that shows on the students' performance and understanding of the concepts. As mentioned in the introduction and in addition to the aspects of content, the impact of combining physical and virtual investigations and the sequence in which students conduct them may depend on student factors such as prior knowledge and conceptions, age and developmental level (Chen \& Chang, 2016; Giddens, 2014; HardenThew \& Lawson, 2015; Jegatha, Baskaran, \& Kannan, 2014; Rogowsky, Calhoun, \& Tallal, 2015; Tan \& Laswad, 2015).

Based on our results and previous studies, we believe that the success of using a combination of physical and virtual experiments likely depends on many factors. Perhaps most importantly, the success of a particular sequence in supporting student learning is influenced by the goals and designed affordances of the individual physical and virtual activities; with physical and virtual activities designed with different goals in mind, the benefit of a particular sequence of activities may differ. This may also be a factor in explaining differences in the overall effectiveness of combining physical and virtual experiments; the more each form of activity takes advantage of the different affordances of physical and virtual artifacts for learning, the more likely we are to see benefits in combining them. The roles that these factors may play will be explored in future research.

\section{Conclusion}

In this study, exclusive physical or virtual activities performances were compared to the comprehensive activities. It was found that comprehensive activities, in any sequence, produce a better understanding of the physical concepts and outperform any exclusive activity. Although the comprehensive approach was more efficient than any exclusive activity, however, it is shown that sequences for which activities were introduced to students are important and affect the learning outcomes. Activities should not only be very well though and carefully designed, but should also be presented to students in an appropriate sequence depending on the concepts in question. It was confirmed that this sequence depends on the degree of abstraction of the experiment itself.

\section{Acknowledgments}

I would like to thank all the teaching assistants for their participation and help in this study. I am grateful for the trust they gave me to design and develop all the simulation based activities for physics II. I am also grateful to the PI (Petroleum Institute) and ADNOC (Abu Dhabi National Oil Company) for the excellent work environment and for the financial support in all our research activities. 


\section{References}

Carmichael, A. (2010). Comparing the effects of physical and virtual experimentation sequence on students' understanding of mechanics. Annual Meeting of the American Educational Research Association Denver, April 30-May 4, 2010.

Chen, S.Y., \& Chang, L.P. (2016). The influences of cognitive styles on individual learning and collaborative learning. Innovations in Education \& Teaching International, 53(4), 458-471.

Couture, M. (2004). Realism in the design process and credibility of a simulationbased virtual laboratory. Journal of Computer Assisted Learning, 20(1), 40-49.

Cummings, K., Marx, J., Thornton, R., and Kuhl, D. (1999). Evaluating innovations in studio physics, Am. J. Phys. 67: S38-S44.

de Jong, T., Linn, M., Zacharia, Z. C. (2013). Physical and virtual laboratories in science and engineering education. Science, 340, 305-308.

Finkelstein, N. D., Adams, W. K., Keller, C. J., Kohl, P. B., Perkins, K. K. Podolefsky, N. S., Reid, S., \& LeMaster, R. (2005). When learning about the real world is better done virtually: A study of substituting computer simulations for laboratory equipment. Phys. Rev. ST Phys. Educ. Res. 1, 010103.

Furtak, T., \& Ohno, T. (2001). Installing Studio Physics, the Physics Teacher, 39, 11.

Giddens, D. (2014). Detailed record: designing effective library tutorials: a guide for accommodating multiple learning styles (Chandos Learning and Teaching Series). Australian Library Journal, 63(1), 54-55.

Guo, Z., Li, Y., \& Stevens, K. (2012). Analyzing students' technology use motivations: an interpretive structural modeling approach. Communications of the Association for Information Systems, 30(14), 199-224.

Harden-Thew, K., \& Lawson, R. (2015). Book review: Learning style perspectives: impact in the classroom. Journal of University Teaching \& Learning Practice, 12(1), 1-2.

Huppert, J., Lomask, S. M., \& Lazarowitz, R. (2002). Computer simulations in the high school: Students' cognitive stages, science process skills and academic science process skills and academic achievement in microbiology. International Journal of Science Education, 24(9), 955-979.

Jaakkola, T., \& Nurmi, S. (2008). Fostering elementary school students' understanding of simple electricity by combining simulation and laboratory activities. Journal of Computer Assisted Learning, 24(4), 271-283.

Jegatha, D. L., Baskaran, R., \& Kannan, A. (2014). Learning styles assessment and theoretical origin in an E-learning scenario: a survey. Artificial Intelligence Review, 42(4), 801-819.

Klahr, D., Triona, L. M., \& Williams, C. (2007). Hands on what? The relative effectiveness of physical versus virtual materials in an engineering design project by middle school children. Journal of Research in Science Teaching, 44(1), 183203.

Koretsky, M.D., Kelly, C., \& Gummer, E. (2011). Student perceptions of learning in the laboratory: comparison of industrially situated virtual laboratories to capstone physical laboratories. Journal of Engineering Education, July 2011.

Linn, MC, Lee, HS, Tinker, R., Husic, F., \& Chiu, JL. (2006). Teaching and assessing knowledge integration in science. Science, 313(5790), 1049-1050.

Merchant, Z., Goetz, E.T., Cifuentes, L., Keeney-Kennicutt, W., \& Davis, T. (2014). Effectiveness of virtual reality-based instruction on students' learning outcomes in K-12 and higher education: A meta-analysis. Computers \& Education, 70, 29-40. 
Miner, D.D. (2010). Inquiry-based science instruction-what is it and does it matter? results from a research synthesis years 1984 to 2002. Res. sci. Teach., 47, 474.

US Department of Education. (2011). Technology impact on learning. Retrieved from http://bit.ly/2nK28Md.

Perkins, K. K., Adams, W., Finkelstein, N. D., Dubson, M., LeMaster, R., Reid, S., \& Wieman, C.E. (2006). PhET: Interactive simulations for teaching and learning physics. The Physics Teacher, 44.

Postman, N. (1995). The end of education: redefining the value of school. New York: Alfred A. Knopf.

Prince, M. (2004). Does active learning work? A review of the research. J. Engr. Education, 93(3), 223-231.

Renken, M.D., \& Nunez, N. (2013). Computer simulations and clear observations do not guarantee conceptual understanding. Learning and Instruction 23, 10-23.

Ross, S., Morrison, G., \& Lowther, D. (2010). Educational technology research past and present: Balancing rigor and relevance to impact school learning. Teaching and Teacher Education, 26(3), 540-546.

Rogowsky, B.A., Calhoun, B. M., \& Tallal, P. (2015). Matching learning style to instructional method: effects on comprehension. Journal of Educational Psychology, 107(1), 64-78.

Tan, L. M., \& Laswad, F. (2015). Academic performance in introductory accounting: do learning styles matter? Accounting Education, 24(5), 383-402.

Sorensen, C. M., Churukain, A. D., Maleki, S., \& Zollman, D. A. (2006). The new studio format for instruction of introductory physics, Am. J. Phys., 74(12), 1077.

Zacharia, Z. C., \& Anderson, R. (2003). The effects of an interactive computer-based simulation prior to performing a laboratory inquiry-based experiment on students' conceptual understanding of physics. American Journal of Physics, 71(6), 618-629.

Zacharia, Z. C. (2005). The impact of interactive computer simulations on the nature and quality of postgraduate science teachers' explanations in physics. International Journal of Science Education, 27(14), 1741-1767.

Zacharia, Z. C., Olympiou, G., \& Papaevripidou, M. (2008). Effects of experimenting with physical and virtual manipulatives on students' conceptual understanding in heat and temperature. Journal of Research in Science Teaching, 45(9), 1021-1035. 